\title{
Cantos da Tríplice Aliança traduzidos do náhuatl clássico para o português ${ }^{1}$
}

\author{
Sara Lelis de Oliveira ${ }^{2}$
}

\begin{abstract}
Resumo: Tradução inédita de dois cantos dos Cantares mexicanos [fls. 1f a 85f] para o português brasileiro referentes às folhas 17 frente, 17 verso e 18 frente. Atualmente o manuscrito encontra-se conservado no Fundo Reservado da Biblioteca Nacional do México (BNM) e é o primeiro dos treze opúsculos reunidos no volume MS 1628 bis. Os Cantares foram escritos em náhuatl clássico, língua indígena franca transcrita da forma oral para a escrita em alfabeto latino no âmbito da catequização de indígenas. Por conseguinte, os cantos tradicionais foram deturpados com, por exemplo, a introdução de elementos católicos tanto em náhuatl - a partir de neologismos - quanto em espanhol. Os dois cantos apresentados são o segundo e o terceiro de um conjunto de 24 cantos [fls. 16v a 26v] que aludem à tradição oral cultivada pela Tríplice Aliança, última elite indígena a ocupar o poder antes da Queda de Tenochtitlan (1521). Neles são exaltadas divindades eliminadas e/ou substituídas pelo Deus cristão e são comemoradas vitórias em guerras passadas.
\end{abstract}

Palavras-chave: Cantares mexicanos, Tríplice Aliança, náhuatl clássico, português, tradução.

\begin{abstract}
This is the first translation into Brazilian Portuguese of two songs of the Cantares mexicanos [folios $1 \mathrm{f}$ to $85 \mathrm{f}$ ] related to the folios 17 front, 17 verse and 18 front. The manuscript is currently preserved in the Reserved Fund of the National Library of Mexico and is the first of thirteen booklets collected in the volume MS 1628 bis. The Cantares were written in classic Nahuatl, an indigenous lingua franca transcribed from the oral form into the Latin alphabet in the context of the catechization
\end{abstract}

1 O presente trabalho foi realizado com apoio da Coordenação de Aperfeiçoamento de Pessoal de Nível Superior - Brasil (Capes) - Código de Financiamento 001.

2 Candidata a Doutora no Programa de Pós-Graduação em Literatura (PÓSLIT) da Universidade de Brasília (UnB). Doutorado-sanduíche em Estudos Mesoamericanos na Universidad Nacional Autónoma de México (UNAM) com apoio CAPES. Mestre em Estudos da Tradução e tradutora pela UnB. E-mail: saralelis@gmail.com. 
of indigenous peoples. Therefore, traditional songs were distorted by, for instance, the introduction of Catholic elements both in Nahuatl -from neologisms- and in Spanish. The two songs will be presented are the second and third of a set of 24 songs [folios 16v to 26v] that allude to the oral tradition cultivated by the Triple Alliance, the last indigenous elite to occupy power before the Fall of Tenochtitlan (1521). In them are exalted divinities eliminated and/or replaced by the Christian God and victories in past wars are celebrated.

Keywords: Cantares mexicanos, Triple Alliance, classic Nahuatl, Portuguese, translation.

\section{Apresentação}

Os Cantares mexicanos consistem nas primeiras 85 folhas do volume MS 1628 bis conservado no Fundo Reservado da Biblioteca Nacional de México (BNM) ${ }^{3}$. Trata-se do primeiro manuscrito do total de treze ${ }^{4}$ compilados no período colonial da Nova Espanha, e é uma das testemunhas literárias da catequese implementada no Altiplano Central do México e das consequentes políticas linguísticas empregadas por missionários franciscanos no propósito de catequização e ocidentalização de nativos sobreviventes do processo da Queda de Tenochtitlan (1519-1521) e mestiços. Compõe-se de 92 cantos $^{5}$ escritos no chamado "náhuatl clássico", língua-veículo da catequese - ou língua geral - adotada pelos franciscanos na região, forjado a partir da transcrição de uma língua indígena franca - cujo nome é desconhecido - para o alfabeto latino e a partir da depuração de cultura e crenças contrárias ao catolicismo.

3 O manuscrito encontra-se na íntegra na página da BNM para consulta. Disponível em: https:// catalogo.iib.unam.mx/F/XGCTAE5UASQQ22CR6N8IGXG5MJAUYSXRKFQE14A4143C16TNTD-14565? func $=$ full-set-set\&set number $=011228 \&$ set entry $=000052 \&$ format $=999$ Acessado em: 05/09/2020.

4 São eles: 1. Cantares mexicanos; 2. Kalendario mexicano, latino y castellano; 3. Arte divinatoria o tonalámatl; 4. Ir.pebua in neixcuitilmachiotl in itentzinco pobui cenquizca yectlaceliliztli Sacramento; 5. Plática indiferente para donde quiera; 6. Hic est panis qui de caelo descendit; 7. Domine modo filia mea deffuncta est, sed veni, impone manun tuam super eam e viver, Math. 9; 8. Teoyahuatlahua Huitrilopochtli. Cuespali buan coyotl miquistli ocelotl cobuatl; 9. Santi estote sicut et ego Sanctus sum Dominus Deus vester, Levit[icus] 19; 10. Tlalnamiquizliz miquitzonquizaliztli; 11. Nican ompebua yn inemilitżin ibuan imiquilitz̧in in cenquizca mabuiztililoni Apostol San Bartholome; 12. Nican ompebua y cacanillatolli yn quitlali ce tlamatini ytoca Esopo: ye techmachtia yn nehmatcanemiliztli; 13 . La bistoria de la Pasión de Ntro. Señor Jesuchristo en lengua mexicana (LEÓN-PORTILLA, 2011, p. 17-19).

5 LEÓN-PORTILLA, 2011, p. 223. 
Os Cantares manifestam uma mudança drástica em parte da Mesoamérica ${ }^{6}$ devido à destituição do Império Mexica por castelhanos e aliados indígenas e, em consequência, ao empreendimento da empresa catequética em cumprimento à determinação papal de $1493^{7}$. No período pré-hispânico, os cantos incorporavam em suas letras a lógica da cosmovisão indígena e eram entoados com o acompanhamento de música, dança e, por vezes, representados em uma performance teatral. No período colonial, sofreram o traslado à forma escrita como resposta às decisões estabelecidas ao longo de quase 20 anos no Concílio de Trento (1545-1563) - em articulação com a práxis de campo missionária - e, sobretudo no Segundo Concílio, as quais convocavam os missionários para a elaboração de materiais para catequizar na língua geral. Neste sentido, os cantos assumiram uma forma escrita que desarticulou sua dinâmica oral e a cosmovisão da língua indígena franca, bem como sofreram a introdução de elementos da religião católica que engendraram um manuscrito truncado tanto com relação à forma quanto ao conteúdo, passando a integrar os diversos materiais produzidos com fins de difusão da doutrina cristã.

Sustenta-se a hipótese de que os Cantares foram elaborados no âmbito do Imperial Colégio de Santa Cruz de Tlatelolco, centro de ensino arquitetado por missionários franciscanos como método para inculcar a religião católica e as tradições europeias nos indígenas desde pequenos e, assim, utilizá-los como mão de obra para difundir a religião. O Colégio foi um espaço fundamental para a elaboração de diversos manuscritos em náhuatl clássico, tarefa delegada a jovens trilíngues e escrivães formados no Colégio sob o trivium e quadrivium e a doutrina católica. A compilação provavelmente ocorreu entre os referidos jovens e informantes anciãos que, mais resistentes à conversão, assegurariam uma transmissão das antigas tradições sem muitas interferências estrangeiras para, enfim, eliminá-las e adulterá-las no traslado para o manuscrito em náhuatl clássico. Embora não haja indícios que comprovem, pelo contexto histórico da época atribui-se a supervisão e subscrição dos Cantares a Bernardino de Sahagún (c. 1499-1590) ${ }^{8}$, franciscano obcecado pela adulteração dos cantos cuja linguagem, segundo ele, era um "esconderijo do diabo" (2016, p. 168).

6 Conceito cunhado em 1943 para designar uma superárea pré-hispânica que, atualmente, inclui “a metade meridional do México, toda Guatemala, Belize, El Salvador, a parte ocidental de Honduras, a costa pacífica de Nicarágua e o noroeste de Costa Rica” (LÓPEZ AUSTIN e LÓPEZ LUJÁN, 2018, p. 75 , tradução minha).

7 GÓMEZ CANEDO, 1988, p. 57.

8 GARIBAY, 2007, p. 153; BIERHORST, 1985, p. 9; LEÓN-PORTILLA, 2011, p. 183. 
Não por isso os Cantares deixam de revelar um aspecto cultural desenvolvido durante séculos no território mesoamericano. Entretanto, o processo de transformação da forma oral para a forma escrita, motivado principalmente pela erradicação de idolatrias, transparece principalmente a confecção de um documento que manifesta, em sua linguagem, um fenômeno ocorrido na Nova Espanha intitulado "nepantlismo" (TRONCOSO PÉREZ, 2011, p. 383). Trata-se de uma categoria antropológica e linguística derivada do vocábulo "nepantla", proferido por um indígena (DURÁN, 2006, p. 237) para expressar que estava em um entre-lugar, em um limbo entre as antigas crenças proibidas e a assimilação do catolicismo. O manuscrito conta com aspectos da tradição oral mesoamericana, porém a partir da fusão de duas tradições, a indígena e a ocidental que, por sua vez refletem a experiência indígena de catequização: um processo de assimilação paulatino da religião católica que talvez nunca tenha se concretizado como conversão.

Os cantos apresentados em versão bilíngue náhuatl-português são inéditos ${ }^{9}$ e ocupam as folhas 17 frente, 17 verso e 18 frente dos Cantares. Aludem à tradição oral cultivada pela Tríplice Aliança, última elite indígena a ocupar o poder na Mesoamérica formada pelos governantes de México-Tenochtitlan, Acolhuacan e Tlalhuacpan. Neles são exaltadas divindades eliminadas e/ou substituídas pelo Deus cristão mediante neologismos em náhuatl ou outras entidades católicas em língua espanhola, manifestando a intervenção de trilíngues e escrivães ao longo da confecção do manuscrito, e são comemoradas vitórias em guerras passadas por vezes sob forma de metáfora, confirmando a hipótese de Sahagún de que os cantos guardavam uma linguagem contrária à doutrina católica. Além disso, mediante a tradução observa-se nos cantos a presença de rastros da oralidade e do entorno semiótico que conformava a performance ritual indígena em seu contexto vivo. A tradução para o português foi motivada por um projeto cujas escolhas objetivam um texto oralizado, bem como a manifestação das intervenções dos trilíngues que engendram o caráter "nepantla" dos Cantares.

9 A primeira tradução de alguns cantos dos Cantares foi realizada por Marcos Caroli Rezende (1995), investigador e professor da Universidad de Santiago de Chile. Uma entrevista com o químico e tradutor está disponível em: https:// periodicos.ufff.br/index.php/ronai/article/view/30276/20842. Acessado em: 05/09/2020. 


\section{Eis aqui o princípio, quando se expressam os cantos que entoavam nos palácios reais de México-Tenochtitlan ${ }^{10}$, Acolhuacan $^{11}$ e Tlalhuacpan ${ }^{12}$, para que os governantes saíssem e se divertissem}

\section{Canto XXI}

[17f, 1. 20] Resplandece, ieeuaia ${ }^{13}$, a árvore florida ${ }^{14} \mathrm{da}$ amizade

No princípio, um banquete se fez

A nobreza permanece aqui, permanece aqui...

Verei bravura, valentia e grandeza

Empobreço-me aqui, uia

Somente a miséria permanece aqui, ouaia ouaia ouaia...

Pássaro-espada ${ }^{15}$, iieuaia, pássaro-flecha, o senhor vem voando, Ipalnemohuani ${ }^{16}$, ai

Lá detém-se totalmente

No seu lugar, seus montes, seu lugar

O senhor purifica-se, agita-se, no lugar dos músicos aqui, no lugar dos músicos já aqui...

Dono dos montes, da terra branca

pequena pena, preciosa garça

Purifica-se, agita-se na terra dos músicos...

10 Cidade-sede do Império Mexica/Asteca, povo supremo da Tríplice Aliança.

11 Literalmente, "Lugar dos senhores da água", onde o governante Neçahualcóyotl, aliado aos mexicas, consolidou um palácio.

12 Região dos tepanecas, povo que cultivava a mesma língua-cultura dos mexicas, a quem eram aliados. O governante chamava-se Totoquihua.

13 Partícula de oralidade entre as várias: "uia", "ouaia ouaia”, "aiieue”, "ieeuaio".

14 Possível metáfora para referir-se à dualidade criadora masculina e feminina Ometecuhtli e Omecíhuatl, respectivamente. A "árvore florida" localizava-se no lugar mítico de Tamoanchan, "lugar da criação" (JOHANSSON, 2015, p. 68).

15 Possível referência a Huitzilopocbtli, deus da guerra cultuado pelos mexicas que os protegia de seus inimigos.

16 Em náhuatl, "aquele por meio de quem se vive". Neologismo criado para substituir a multiplicidade de deuses/as mesoamericanos por um único. 
Apropriou-se de turquesas

É soldado valente, aiiaue

Sobre o trono de jaguar os senhores estão, dentro da casa de verão, reverenciados Mocteçumatzin ${ }^{17}$ e Totoquihuatzin $^{18} \ldots$

\section{[17v] Como é dito por Ipalnemohuani?}

Ainda em um instante sobre seu petate ${ }^{19}$

Eles, Deus, uia

Lá vocês e o chichimeca, neto de Neçahualcoyotl ${ }^{20}$, os detiveram ouaia ouaia...

Desbarata as flores ${ }^{21}$ inimigas, ieeuaio

Algo resplandece

Todas murcham

Valentia, grandeza

Quantos irão a algum lugar, quantos viverão contigo, perto de ti? Eles, Deus, uia Porém, lá longe estão, ouaia ouaia...

Foram para Quenonamican ${ }^{22}$, uia

o reverenciado senhor Tlacahuepantzin ${ }^{23}$

e o senhor Ixtlilcuecháhuac ${ }^{24}$

Pouco tempo de vida na presença deles, uia...

Mas lá estão, na terra despovoada, ouaia ouaia...

17 Nome de dois soberanos de Tenochtitlan. Mocteçuma II foi o último governante indígena antes da chamada Conquista do México (1519-1521).

18 Senhor de Tlacopan, senhorio aliado de México-Tenochtitlan.

19 Espécie de tapete feito de palma para deitar-se.

20 Governante de Texcoco, aliado dos mexicas.

21 Neste caso, a hipótese de que a flor era uma metáfora para flechas e armas.

22 Um dos nomes de lugar que designa o além, após a morte física.

23 Irmão de Moctecuma morto em uma batalha contra os chalcos.

24 Outro irmão de Moctecuma também morto em uma batalha contra os chalcos. 


\section{Canto XXII}

[17v, 1. 11] Árvore florida

No princípio, seu lar

Deus lá resplandeceu

No lugar da garça branca de quetzal

Sobrevém o çaquan

Chegam o xiuhquecho ${ }^{25} \mathrm{e}$

o honroso pássaro quetzal, ouaia ouaia...

Todos vêm de lá, de Nonohualco ${ }^{26}$

No mundo, há pássaros quechol e criaturas de Ipalnemobuani

Sobrevém o gaquan

Chegam o xiuhquetzal e

o honroso pássaro quetzal, a ouaia ouaia...

Petate de flores e de xiuhquechol

Onde se estende, dentro da casa dos amoxtin ${ }^{27}$ e das turquesas

Onde se reclinam eles, Ipalnemohuani

O resplandecer da alva vela-os

Os pássaros quechol e xiubtototl despertam os senhores,

amanhecendo o dia com seus cantos, ouaia ouaia ouaia...

Lá gorjeia seu quechol

Os pássaros trinitzcan ${ }^{28}$ e tlauhquecho ${ }^{9}$ despertam os senhores

e lhes fazem sombra até à noite

Amanhecendo o dia, canta o xiubtototl, ouaia ouaia ouaia...

Tamoanchan ${ }^{30}$, seu lar, flores

De lá aprumados vêm

25 Ave típica do território mesoamericano.

26 Bairro de México-Tenochtitlan.

27 Material interpretado pelos castelhanos como livro ou pintura, vocábulos pelos quais costuma ser traduzido.

28 Ave típica do território mesoamericano, apreciada por suas ricas penas.

29 Variedade de quechol.

30 Lugar mítico-terrenal situado nas regiões septentrionais da Mesoamérica de onde se supõem originários os mexicas. 
nossos senhores: o senhor, reverenciado Mocteçumatzin, e o reverenciado Totoquihuatzin

Chegam aqui, onde se localiza o pátio florido

Os senhores entoam bem nossos belos cantos, "iapa iatantilililin" 31

Vêm à casa das pinturas ${ }^{32}$, ouaia ouaia

De forma que os senhores se movem, com seus tambores e chocalhos floridos

Vêm aqui, onde se localiza o pátio florido

Os senhores bem entoam nossos belos cantos...

Canta "ililin" ${ }^{33}$ em Ilihuiacan ${ }^{34}$

O que está gorjeando o quechol? Eles, Deus

Em Huitzilan ${ }^{35}$, em Ilihuiacan ele liba o pólen, uia

do coração brota uma flor do jardim, uma flor do jardim...

[18f, 11. 1 a 3] Sim, vem, já vem a borboleta, uia, vem voando de lá

Vem com asas grandiosas

Sobre as flores ela vive e liba o pólen

Do coração brotam flores no jardim, ouaia ouaia ouaia...

31 Possível onomatopeia para o canto de algum pássaro.

32 Local onde se confeccionavam amoxtin.

33 Possível onomatopeia para o canto do quechol.

34 Lugar onde o quechol canta "ililin".

35 Lugar dos colibris. 


\section{Nican ompehua in motenehua melahuac cuicatl in mehuaya tecpan Mexico Acolhuacan Tlalhuacpan inic imelel quiçaya tlahtoque ${ }^{36}$}

[17f, 1. 20] Yan cuecuepontimani yeebuaya a in icniubxochinquabuitl y cohuayotly nehnelhuayo mochiubtoc ya in tecpillotl a ica mahmani ye nican etc.

Can niquittaz quaubyotl mahuiçotl oceloyotl in ninotolinia ya nica huia in çan icnoyotl ica mahmani ye nican obuaya obuaya.

Macuabuitototl yiehuaya çan tlacochtlin tototl tiiapatlantibuitz. Ipalnemoa o aya timoquetzacon mochial imanca motraqual imanca timopohpoa ya çan timotzetzeloa ya buebuetitlan ye nican etc.

Can tepehuin tiçatl in ibuitl çan ca quetralaztatl timopopoyahuan timotzetzeloa ya etc.

Yc onxiubycuiliubtoc inquaubpetlatl ayyahue a oceloicpall ipanamoncate yn xopancalitic in Moteuccomatzin in Totoquibuatzin etc.

[17v] Quen quittoan Ipalnemoa aoc achitrinca in ipetlapan in yehuan Dios huian a inoncan amechycnocaubtehuac chichimecatl Neçahualpilla obuaya obuaya.

Yaoxochitl y moyahua yeehuayo cequi cueponi ixquich oncuetlabuia quaubyotl oceloyotl buia quexquich oya y quexquich oc nemiquiuh motloc monabuac $i$ i yebuan Dios buia y yece ye oncan a obuaya obuaya.

Obuiloac Quenonamican huiya in Tlacahuepantrin in tlatohuani ya Ixtlilcuechabuac ye ocuel achic onnemico

ixpan in yehuan Dios huiya ixtlabuacan yece ye oncan obuaya etc.

[17v, 1. 11] Xochinquabuitl y nelhuayocan a ichan in Dios oncan cueponticac i quetzalmiahuayocan bualaci an çaquan ye'co xiuhquechol mahuiquin quetzaltototl a obuaya etc.

In moch ompa anbuitze in ye Nonobualco ya in cemanabuac y in amiquecholbuan Ipalnemoani in amitlachibualhuan bualacia çaquan ye'co xiuhquechol mabuiquin quetzaltototl etc.

Xiuhquecholxochinpetlacotl oncan ya mani a xiuhamoxcalico oncan ya onoc i yehuan Dios i Tlabuizcallin quitztoco mitronyaixtia in moquecholbuan çan ca xiubtototl tlathuian tra'trian obuaya etc.

Onchachalaca moquechol mitronyaixitia mitroyohuia trinitzcan tlaubquechol çan ca xiubtototl tlathuian tratzian ohuaya obuaya.

36 A paleografia tem como base a decifração dos caracteres por León-Portilla (2011), a qual foi comparada pela tradutora com o manuscrito da BNM para esta apresentação final. 
Yn tamoan icha xochitl ye icaca ompa ye ya huitze yan toteuchua huiya tiMoteuccomatzin, in

Totoquibuatzin in anme'coque ye nican xochiithualli ymanca buel anconehua i yectlin anmouic yapa yatantilililin tlacuicuilolcaliticpan abuitze obuaya obuaya.

$O$ anca amehuan in ancoholinia anmoxochibuehueub moxochayacachy in ame'coque ye nican xochithualli manca buel anconehua etc

Ylilincohui ylibuancano tleon in quittoa a in quechol yehuan Dios y buitzilan i ylibuiacan o ye ontlachichina ma ya buia ye i yolcueponi ya xochitla etc.

[18f, 11. 1 a 3] Can ye huitzye huitz in papalotl buia ye ompatlantibuitzye mocogoubtibuitz xochiticpac nemi a ye ontlachichina ma yahuia ic y iolcueponia xochitla obuaya etc

\section{Contexto histórico dos cantos}

Os cantos XXI e XXII dos Cantares manifestam exaltações a divindades mesoamericanas eliminadas e/ou substituídas, e a governantes de MéxicoTenochtitlan, Acolhuacan e Tlalhuacpan em virtude das conquistas passadas que os fortaleceram como Tríplice Aliança: instituição política que imperou sobre quase todo o território no pós-clássico tardio da Mesoamérica (1200/1300 a 1521 d. C). Era formada por três grupos étnicos de forte caráter ideológico-religioso: os colhuas-mexicas em México-Tenochtitlan, os toltecas-acolhuas em Texcoco, e os otomíes-tepanecas em Tlacopan (HERRERA, LÓPEZ AUSTIN e MARTÍNEZ, 2013, p. 28).

Uma das guerras empreendida e vencida que determinou a Tríplice Aliança foi a guerra contra Azcapotzalco, aproximadamente em 1428:

O nome Tríplice Aliança, bastante usado, diz respeito, indubitavelmente, ao uso militar que se deu à instituição uma vez que os povos dominados pelo poder de Azcapotzalco livraram-se de Maxtlan ao vencerem os tepanecas no ano 1428. A aliança dos vencedores se institucionalizou [...] desde $1433^{37}$ (HERRERA, LÓPEZ AUSTIN e MARTÍNEZ, 2013, p. 21, tradução minha).

37 Texto em espanhol: "El muy usado nombre de Triple Alianza corresponde, indudablemente, al uso militar que se dio a la institución una vez que los pueblos dominados por el poder de Azcapotzalco se libraron de Maxtla al vencer a los tepa- necas en el año de 1428. La alianża de los vencedores se institucionalizó, [...] desde 1433". 
Os mexicas, por meio de Mocteçuma, eram os líderes principais do trio de governantes, mas os tributos cobrados dos povos subjugados - propósito central da Tríplice antes mesmo da expansão territorial- eram divididos entre as três partes. Cada um possuía uma função de poder específica que era de estrutura cósmica: “... os colhua-mexicas como guerreiros, pertencentes ao Sol, os acolhuas se dedicavam a funções intelectuais (legislativas, literárias, de engenharia), pertencentes ao Céu Alto, e os tepanecas exerciam funções de produção e comércio, pertencentes ao infra-mundo" 38 (HERRERA, LÓPEZ AUSTIN e MARTÍNEZ, 2013, p. 28).

Dos três povos, os mexicas eram os supremos por seu domínio militar. À época, eram conhecidos como os "grandes guerreiros" e as batalhas consistiram no sustento do poder regional. Por meio das guerras, garantiam as penas do precioso pássaro quetzal, pedras preciosas e metais para o artesanato da elite indígena, as quais provinham de outros povos. Os cantos referem-se, essencialmente, às conquistas anteriores que consolidaram historicamente a coalizão, bem como a relação de agradecimento com divindades pela proteção e vitórias concedidas desde sua chegada na então México-Tenochtitlan.

O canto XXI narra uma vitória da Tríplice Aliança e é oferecido em honra à nobreza. Neste, os três governantes são mencionados e exaltados em razão de uma guerra que ocorreu "lá" (em Chalco): "Lá, vocês e o chichimeca, neto de Neçahualcoyotl, os detiveram, ouaia ouaia”. A guerra em questão refere-se à batalha contra os chalcos, povo que passou a ser tributário da Tríplice Aliança após a derrota.

O indício do canto que aponta para este acontecimento histórico encontra-se na morte de Tlacahuepantzin e Ixtlilcuecháhuac, ambos irmãos de Mocteçuma:

Foram para Quenonamican, uia

o reverenciado senhor Tlacahuepantzin e o senhor Ixtlilcuecháhuac

Pouco tempo de vida

na presença deles, uia

Mas lá estão, na terra despovoada, ouaia ouaia... ${ }^{39}$

(Canto XX, tradução de Sara Lelis, 2020).

38 Texto em espanhol: “... Los colbua-mexicas como guerreros, pertenecientes al Sol; los acolbuas dedicados a funciones intelectuales (legislativas, literarias, de ingeniería), pertenecientes al Cielo Alto, y los tepanecas ejerciendo funciones de producción y comercio, pertenecientes al Inframundo".

39 Texto em náhuatl: "Ohuiloac Quenonamican buiya in Tlacabuepantzin in tlatobuani ya Ixtlilcuechabuac ye ocuel achic onnemico ixpan in yehuan Dios huiya ixtlabuacan yece ye oncan obuaya etc". 
A vitória da Tríplice Aliança deve-se à morte de Tlacahuepantzin, que comete suicídio e determina, com um tipo específico de autosacrifício, a submissão dos chalcas aos mexicas (JOHANSSON, 2014, p. 89).

O canto XXII é alegre e não aborda especificamente nenhuma guerra vencida. Trata-se da conformação dos mexicas como um grande povo em Tamoanchan, lugar de onde afirmam ser originários após se desvincularem de outros povos e constituírem sua própria cultura (JOHANSSON, 2015, p. 72-74).

A letra do canto exalta o "nascimento" dos mexicas como povo uno em Tamoanchan, lugar físico-metafísico onde Ometéotl, princípio dual criador do universo e pai-mãe de todas as divindades - no canto substituído por Ipalnemohuani ou Deus -, criou "todas as coisas":

Árvore florida

No princípio, seu lar

Deus lá resplandeceu

No lugar da garça branca de quetzal

Sobrevém çaquan

Chega xiubquechol e

o honroso pássaro quetzal, ouaia ouaia... ${ }^{40}$

(Canto XXII, tradução de Sara Lelis, 2020).

Há, em toda a entoação do canto, uma alternância entre o lugar físico e o lugar metafísico:

Tamoanchan, seu lar, flores

De lá vêm aprumados nossos senhores:

o senhor, reverenciado Mocteçumatzin,

e o reverenciado Totoquihuatzin

Chegam aqui, onde se localiza o pátio florido

Os senhores bem entoam nossos belos cantos "iapa iatantilililin"

Vêm à casa das pinturas, ouaia ouaia ${ }^{41}$.

(Canto XXII, tradução de Sara Lelis, 2020).

40 Texto em náhuatl: "Xochinquabuitly nelhuayocan a ichan in Dios oncan cueponticac i quetzalmiabuayocan bualaci an çaquan ye'co xiubquechol mabuiquin quetzaltototl a obuaya etc".

41 Texto em náhuatl: "Yn tamoan icha xochitl ye icaca ompa ye ya buitze yan toteuchua buiya tiMoteuçomatzin, in Totoquihuatzin in anme'coque ye nican xochiithualli ymanca buel anconebua i yectlin anmovic yapa yatantilililin tlacuicuilolcaliticpan abuitze obuaya obuaya". 
O contexto histórico da canção é festivo, salientando a grandeza da cultura mexica. Uma hipótese, derivada da interpretação, é de ser este canto bastante musical em virtude das aves - xiuhquetzal, quetzal, çaquan - que gorjeiam junto aos cantores e aos instrumentos.

\section{Apresentação em verso da tradução para o português}

A apresentação verso dos Cantares na tradução para o português pretende aludir, esteticamente, a uma possível forma cantada no período pré-hispânico. Nesta proposta de versificação, a recriação de cada um dos versos dos cantos depende dos sentidos revelados na tradução que possibilitam a fragmentação semântica de cada unidade frásica. A composição em verso, por vezes, também depende dos rastros da performance cantada que formavam parte dos cantos antigos. Para o registro escrito foram transcritos para o manuscrito alguns deles, como "ouaia, ouaia", "ieeuaia", "uia", além dos que já integravam a letra dos cantos sob a forma de verbos ou substantivos que apontam para a cena da entoação.

A metodologia para separação dos versos consistiu no paralelismo, recurso linguístico bastante utilizado na poesia (JAKOBSON, 1981, p. 379) que atua como técnica para preservar certa imagem referente aos cantos tradicionais. No caso dos Cantares, trata-se de um paralelismo semântico que organiza o conteúdo e a estrutura de textos de origem oral, mas principalmente reivindica sua condição anterior à colonização da vOz (MONTES DE OCA, 2014, p. 203). O paralelismo permite uma hipótese de recriação da cena da performance que, com o período colonial foi proibida e, no translado dos cantos para a escrita, adquiriu outra organização com a imposição do alfabeto e do livro para determinar um padrão visual e cognitivo (MIGNOLO, 2016, p. 232). O objetivo consiste em uma das tentativas de transpor a dinâmica oral para uma tradução alfabética, sugerindo uma experiência que se organizava em uma linguagem que se construía com um todo semiótico.

\section{Aprendizado do náhuatl clássico}

Meus estudos do náhuatl clássico começaram concreta e sistematicamente no Brasil, em 2018, por conta própria e através de gramáticas modernas da língua. Antes desse ano, havia desenvolvido também individualmente estudos esparsos em 2016 e ao longo de 2017. Iniciei a partir da gramática Nábuatl Práctico ${ }^{42}$ (1992), 
de Fernando Horcasitas (1924-1980), especialista estadunidense em estudos etnográficos do náhuatl. Nela, propõe-se uma introdução à língua voltada para a prática antropológica. $\mathrm{O}$ autor aclara que a obra é um estudo básico, advertindo que o conhecimento do idioma a ser adquirido por essa gramática não é o náhuatl clássico. Trata-se de um "náhuatl moderno" que poderia ser falado e entendido nas diversas variantes da língua de diversas comunidades e regiões do México, as quais não são citadas. A gramática de Horcasitas constituiu uma base para o posterior estudo do náhuatl clássico.

Também no Brasil iniciei os estudos precisamente em náhuatl clássico com o Compendio de la gramática nábuatl ${ }^{43}$ (1976) de Thelma Sullivan (1918-1981), paleógrafa, linguista e tradutora estadunidense dos pares náhuatl-espanhol e náhuatl-inglês, e com Nabuatl as written (2001), de James Lockhart (1933-2014), historiador e tradutor náhuatl-inglês estadunidense. A partir do aprendizado em ambas as gramáticas passei a exercitar a tradução a partir do que já havia adquirido da língua e para desenvolver trabalhos acadêmicos sobre algumas traduções dos Cantares para o português.

No México, na realização do doutorado-sanduíche, empreendi o estudo de Lectura del Nábuatl ${ }^{44}$ (2016), de David Charles Wright Carr, especialista em língua náhuatl e em diversos outros temas relacionados aos povos, histórias e cultura da Mesoamérica. Além dessa, estudei mediante a gramática Introducción a la lengua y a la literatura nábuatt ${ }^{45}$ (1992), de Michel Launey, e de Llave del Nábuatt ${ }^{46}$ (1940), de Garibay Kintana.

Na Escuela Nacional de Antropología e Historia (ENAH), cursei as disciplinas Lengua Nábuatl I e II com o prof. Dr. Salvador Reyes Equiguas. No Museo Nacional de Antropología e História, participei do Seminario de Lengua Nábuatl, ministrado pela prof ${ }^{a}$. Mstra. Carmen Herrera e pelo prof. Dr. Rafael Tena. No período em questão, trabalhamos com a tradução dos livros I e III do Códice florentino ${ }^{47}$, ma-

43 Disponível em: http://www.historicas.unam.mx/publicaciones/publicadigital/libros/gramatica/ cgn_001.pdf Acesso em: 21/03/2020.

44 Disponível em: https://site.inali.gob.mx/publicaciones/libro_lectura_nahuatl/pdf/lectura_del_ nahuatl.pdf Acessado em: 22/03/2020.

45 Disponível em: http://www.vcn.bc.ca/prisons/Launey_1992.pdf Acessado em: 22/03/2020.

46 Disponível em: https://drive.google.com/file/d/1aw8kKrLWiRpcifS0_ToBZxiDJYTteZya/view?fbclid=IwAR2zKmA6POPibifumgdi38gaCPaRbKXtOarjafvjLQybK4penVDo73uo7WE Acessado em: 22/03/2020.

47 Códice florentino. Textos nabuas de Sahagún. Edição fac-símile publicada on-line pela Biblioteca Laurenciada, Florencia, e reproduzida pela Biblioteca Digital Mundial, 1577. Disponível em: https://www. wdl.org/es/item/10096/view/1/392/ Acessado em: 18/03/2020. 
nuscrito supervisionado e subscrito por Sahagún. Na Escola Nacional de Lenguas, Lingüistica y Traducción (ENALLT), cursei um semestre de "náhuatl moderno" (de "masehualkopa", nome da variante de Tlacotenco - Milpa Alta, Cidade do México) com o prof. Sergio Sevilla. A gramática da língua aprendida em sala de aula referia-se ao náhuatl clássico, enquanto a competência oral voltava-se para o masebualkopa, "náhuatl" de seus ancestrais.

O estudo do náhuatl clássico por intermédio de várias gramáticas, em espanhol e inglês ${ }^{48}$, justifica-se pela complementação que uma oferece à outra. Entre si, apresentam diferenças em razão das fontes missionárias e/ou modernas das quais se utilizaram seus autores, e principalmente de suas próprias traduções de manuscritos coloniais, as quais provavelmente manifestaram peculiaridades da língua que alimentaram, posteriormente, a elaboração das gramáticas.

A variedade de gramáticas modernas reflete a diversidade das Artes elaboradas no período colonial $^{49}$, as quais atendiam especificamente o objetivo de aprender a língua para catequizar os indígenas e, por esse motivo, surgiam novas gramáticas com aportes diversos para compreensão da língua. O trabalho missionário de elaboração das gramáticas foi um trabalho coletivo entre os freis que pode ser entendido como um quebra-cabeça cujo resultado - o abarcamento da língua - aconteceria através da união de todas as peças - as Artes:

...embora Olmos, Molina, Del Rincón, Galdo e Carochi aprenderam dos nahuas um idioma de regiões diferentes e o fizeram em um lapso compreendido entre a chegada do primeiro, em 1528, e do último no início do seguinte século, dada a ilação de seus trabalhos, é o processo unitário dos mesmos e não de um deles o que constitui a expressão dos iniciais e sucessivos empenhos de analisar os elementos da antiga lingua, de propor e ajustar sua ortografia e, além de tudo, de indagar e formular as normas básicas de suas articulacóes a partir de modelos emprestados de outras linguas muito estranbas e distantes ${ }^{50}$ (CASTILLO FARRERAS, 2010, p. 26 , tradução e grifos meus).

48 Até o presente momento não há gramáticas de náhuatl clássico em português salvo o pequeno apêndice "rudimentos da Língua Náhuatl" realizado por Rezende (1995, p. 127-131).

49 León-Portilla contabiliza mais de 30 (2017, p. 5).

50 Texto em espanhol: ... aunque Olmos, Molina, Del Rincón, Galdo y Carochi aprendieran de los nabuas un idioma de regiones diferentes y lo bicieron en un lapso comprendido entre el arribo del primero, en 1528, y del último a principios del siguiente siglo, dada la ilación de sus trabajos, es el proceso unitario de los mismos y no uno de ellos lo que constituye la expresión de los iniciales y sucesivos empeños de analizar los elementos de la antigua lengua, de proponer y ajustar su ortografia y, por si fuera poco, de indagar y formular las normas básicas de sus articulaciones a partir de modelos tomados de otras lenguas, muy extrañas y distantes. 
Além de coletivo, também um trabalho de longo prazo uma vez que deveriam dar conta da língua falada em diversas regiões. Neste sentido, a variedades de gramáticas modernas respondem a processos de descoberta da língua tal como no período colonial, mas, na atualidade, através de novas interpretações das Artes e também da tradução dos manuscritos coloniais legados.

Aprender o náhuatl clássico por meio de várias gramáticas fornece diversos aspectos distintos da língua, reduzindo as dificuldades da tradução dos manuscritos antigos. Não obstante, apensar de fundamentais no aprendizado, tanto as Artes quanto as gramáticas (ainda) não garantem um profundo conhecimento do náhuatl clássico. Para tal conhecimento, é essencial a experiência tradutória de diversos manuscritos coloniais, pois é esse contato que possibilita o conhecimento da língua "em funcionamento":

...as gramáticas se centram na análise morfológica e, embora algumas delas oferecem análises da organização sintática de orações simples e de construções compostas, todas privilegiam o estudo da língua como sistema, e não do discurso tal como se manifesta em alguns dos documentos existentes. [...]. E se, para entender um discurso, nunca são suficientes gramáticas e dicionários, menos ainda para entender os giros sintáticos e os sentidos do vocabulário empregado ${ }^{51}$ [...] (HERRERA et. al, 2004, p. 180, tradução e grifos meus).

Essa conclusão é patente na tradução dos Cantares para o português, pois percebeu-se que as gramáticas não abarcam todas as questões linguísticas com as quais se deparam no manuscrito. Por vezes, o que fornece a gramática não é exatamente o que se enfrenta no manuscrito e o tradutor deve aprofundar-se nos estudos culturais para recompor o contexto histórico e tentar solucionar os problemas.

\section{Sobre a tradução para o português}

Os Cantares são cantos enigmáticos em si mesmos. Concorda-se com Sahagún que há, em sua linguagem, algo inacessível. Em efeito, no período pré-hispânico

\footnotetext{
51 Texto em espanhol: "Sin embargo, las gramáticas se centran en el análisis morfológico y aunque algunas de ellas ofrecen análisis de la organización sintáctica de oraciones simples y de construcciones compuestas, todas privilegian el estudio de la lengua como sistema, y no del discurso tal y como se manifiesta en al gunos de los documentos existentes. [...]. Y si para entender un discurso nunca son suficientes gramáticas ni diccionarios, menos lo son para entender los giros sintácticos $y$ los sentidos del vocabula rio empleado en la documentación administrativa y jurídica".
} 
os cantos eram intencionalmente elaborados pela elite indígena com o objetivo de serem compreendidos por uma parcela mínima da sociedade. Essa linguagem parece haver sido um recurso utilizado a favor deles no período colonial para que pudessem manifestar suas próprias crenças livremente:

Entre os indios nabuas, uma linguagem "equivoca", camuflada, serve para transmitir fórmulas, crenças. Recebe inclusive um nome: nabuatlatolli. O suporte verbal é denunciado insistentemente, como se os extirpadores estivessem conscientes de que o acesso à realidade indígena requeria a denominação e a metáfora. De fato, tratam de dominar uma linguagem "dificultosa e quase ininteligível", "não é outra coisa que uma continuação de metaphoras, não só nos verbos, mas também nos nomes substantivos e adjetivos, talvez passe para uma continuada alegoria"52 (BERNARD e GRUZINSKI, 2018, p. 142, tradução e grifos meus).

O hermetismo dos cantos, provavelmente não compreendidos nem mesmo pela população comum pré-hispânica (em náhuatl, os macehualtin), parece ser um aspecto a ser contornado através de estudos antropológicos e históricos que deslocam o conhecimento sobre a Mesoamérica do eixo catequético. Para a tradução, nesse ínterim, houve aprofundamento nessas fontes no propósito de recontextualizar o texto e, assim, identificar as referidas metáforas para uma melhor compreensão do texto e/ou elementos da entoação viva os quais, no texto escrito, carecem de sentido ou referência.

Uma delas é a "árvore florida", localizada no lugar mítico de Tamoanchan ${ }^{53}$, "lugar da criação". Trata-se de uma possível metáfora-idolátrica referente ao princípio dual criador dos nahuas (Ometecubtli e Omecíbuat) que permaneceu no manuscrito talvez pela semelhança de concepção da flor no Cristianismo (ALCÁNTARA ROJAS, 2008, p. 129-130). O conceito de raiz, inerente à "árvore", designa o nascimento/a criação de tudo o que há no mundo na cultura náhuatl. Tamoanchan, por sua vez, denomina o lugar da gestação (JOHANSSON, 2015, p. 68). O neologismo em náhuatl Ipalnemohuani, elaborado para referir-se ao Deus cristão, pode haver sido utilizado para substituir a dualidade masculina e feminina.

52 Texto em espanhol: 'Entre los indios nabuas un lenguaje 'equivoco', camuflado, sirve para transmitir fórmulas, creencias. Recibe incluso un nombre: el nabuatlatolli. El soporte verbal se denuncia insistentemente, como si los extirpadores estuvieran conscientes de que el acceso a la realidad indigena requería la denominación y la metáfora. De hecho, tratan de dominar un lenguaje 'dificultoso y casi ininteligible', "no es otra cosa que una continuación de metaphoras, no sólo en los verbos sino aun en los nombres substantivos y adjetivos, tal vez pasa a una continuada alegoría".

53 Segundo Johansson, a origem etimológica de Tamoanchan suscita discussões desde o século XVI, as quais influenciam nas infinitas traduções para o termo. O linguista oferece várias delas (2015, p. 79). 
Outro exemplo diz respeito à flor, que possuía inúmeros significados segundo suas várias espécies, simbolismos, pinturas, esculturas, propriedades medicinais, culinárias ou de adorno e vestimenta, e também quando serviam de inspiração para os cantos. Doris Heyden (1915-2005), pesquisadora estadunidense da flora pré-hispânica, afirma:

No México antigo, a flora representava a vida, a morte, os deuses, a criação, o homem, a linguagem, o canto e a arte, a amizade, o senhorio, o cativo na guerra, a própria guerra, o céu, a Terra, e um signo calendárico. [...] ...a flor foi um dos elementos básicos na comunicação simbólica pré-hispânica. Assim como a pluma de quetzal e a conta de jade, era sinônimo do que era "precioso"s4 (HEYDEN, 1983, p. 9, tradução e grifos meus).

Nos cantos apresentados identifica-se vários desses significados e mais um, o da flor como símbolo de "arma" (SAUTRON, 2007, p. 258). Em "Desbarata as flores inimigas, ieeuaio/ Algo resplandece/ Todas murcham/ Valentia, grandeza", as "flores inimigas" concernem à vitória contra os chalcos cujas "flores" (armas, flechas) murcharam (não prevaleceram).

A opacidade dos Cantares também se centra nos impactos do traslado de uma forma oral para uma forma escrita. A tarefa tradutória, neste sentido, equipara-se a uma tarefa arqueológica em busca dos rastros performáticos que complementavam as letras no contexto de entoação (LELIS, 2019). Para tanto, foram utilizados os relatos de missionários do século XVI que, para condenar a prática ritual, descreviam com mais ou menos detalhes o que presenciavam. O mais completo que se conhece é o do franciscano Motolinía (c. 1555), no qual ressalta elementos quanto ao espaço de entoação (praças e casas de nobres); à circunstância (celebrações de guerra e religiosas -festas dos "demônios"); aos instrumentos musicais (tambores, entre eles o tepona:t tli); aos atavios (adereços sobre as cabeças e roupas específicas para dançar) e apetrechos (mantas e penas); às coreografias (movimentos bem coordenados, compassos), ao tempo (manhã e noite), aos dançarinos e cantores (a quantidade de pessoas que participava do evento); à música (tonalidades, compassos, intervalos), entre outros detalhes presentes no trecho como alguns juízos de valor (“demônios”) e menções ao que viu (“aqueles dois mestres começam”).

54 Texto espanhol: "En el México antiguo, la flora representaba la vida, la muerte, los dioses, la creación, el hombre, el lenguaje, en canto y el arte, la amistad, el señorío, el cautivo en la guerra, el cielo, la Tierra, y un signo calendárico. [...]... la flor fue uno de los elementos básicos en la comunicación simbólica prehispánica. Igual que la pluma de quetzaly la cuenta de jade, era sinónimo de lo "precioso"." 
Todo esse complexo da cena viva contribui para preencher as lacunas de um texto escrito proveniente da oralidade.

A colonização da língua indígena franca que deu origem ao náhuatl clássico consiste no maior empreendimento de tradução não só dos Cantares, mas de qualquer manuscrito colonial na referida língua geral. Ao entender que o empenho do tradutor recai sobre a compreensão da visão de mundo de uma cultura expressa em uma língua para organizar esse conhecimento em outra língua, de visão de mundo e cultura distintas, enfrenta-se os obstáculos de traduzir língua e cultura deturpadas. Reflete-se, portanto, sobre as reais possibilidades de recuperar este Outro transformado, mas não completamente extinto, por um longo processo de imposição de valores. A tradução figura como uma via privilegiada de escavação da cultura tradicional mediante seu acesso à linguagem que não se refere somente à leitura interpretativa, mas aos modos de significar expressos na língua. Trata-se de um trabalho reflexivo e consciente para escolhas tradutórias que se opõem a dar continuidade ao projeto de apagamento missionário. Acredita-se que esse posicionamento diante de textos coloniais inaugurariam um novo locus de enunciação tanto na área da tradução quanto nos estudos mesoamericanos para a produção de novos conhecimentos sobre uma parcela do passado mexicano.

\section{Referências bibliográficas}

ALCÁNTARA ROJAS, Berenice. In nepapan xochitl: The Power of Flowers in the Works of Sahagún. In: Colors between two worlds. The Florentine Codex of Bernardino de Sahagún. Orgs. Joseph Connors, Gerhard Wolf, Diana Magaloni, Clara Bargellini, Diana Magaloni, Alessandra Russo. Florence: Villa I Tatti, 2008, p. 107-132.

BERNAND, Carmen; GRUZINSKI, Serge (1992). De la idolatría. Una arqueología de las ciencias religiosas. Tradução de Diana Sánchez F. $1^{a}$ reimpresión. México: Fondo de Cultura Económica, 2018.

BIERHORST, John. Cantares mexicanos. Songs of the aztecs. Stanford: Stanford University Press, 1985.

Cantares mexicanos [manuscrito]. In: MS 1628 bis. México: Biblioteca Nacional de México, 85 f. Disponível em: https://catalogo.iib.unam.mx/exlibris/aleph/a23_1/apache_media/ CNVT4T1JK3621B7RUDF8BISVU2EIXJ.pdf Acesso em: 19 abr 2020.

Cantares mexicanos. Paleografia, tradução e notas de Miguel León-Portilla. México: UNAM, Coordinación de Humanidades: Instituto de Investigaciones Bibliográficas: Instituto de Investigaciones Filológicas: Instituto de Investigaciones Históricas: Fideicomiso Teixidor, 2011. CASTILLO FARRERAS, Víctor M. Los conceptos nabuas en su formación social. El proceso de nombrar. México: Universidad Nacional Autónoma de México, 2010. 
DURÁN, Diego (Frei) (1581). Historia de las Indias de Nueva España e Islas de la Tierra firme. Edicão preparada por Ángel María Garibay K. Tomo I. México: Porrúa, 2006.

GARIBAY KINTANA, Ángel María (1953-54). Historia de la Literatura Nábuatl. $3^{a}$ edição. México: Editora Porrúa, 2007.

GARIBAY KINTANA, Ángel María (1940). Llave delNáhuatl. México: Editorial Porrúa, $10^{a}$ edição, 2013. Disponível em: https:/ / drive.google.com/file/d/1aw8kKrLWiRpcifS0_ToBZxiDJYTteZya/view?fbclid=IwAR2zKmA6POPibifumgdi38gaCPaRbKXtOarjafvjLQ ybK4penVDo73uo7WE Acesso em: 22 mar. 2020.

GÓMEZ CANEDO, Lino. Evangelización y conquista. Experiencia franciscana en Hispanoamérica. $2^{a}$ edición. México: Porrúa, 1988.

HERRERA MEZA, María del Carmen, LÓPEZ AUSTIN, Alfredo, MARTÍNEZ, Rodrigo. El nombre náhuatl de la Triple Alianza. Revista Estudios de Cultura Nábuatl, vol. 46, p. 7-35, 2013. Disponível em: http://www.historicas.unam.mx/publicaciones/revistas/nahuatl/ pdf/ecn46/944.pdf Acesso em: 05 set. 2020.

HERRERA, Ma. Del Carmen; MEDINA, Constantino; PERALTA, Valentín; ROCKWELL, Elsie; SANDOVAL, Zazil; VON MENTZ; Brígida. Traducción de documentos en náhuatl: una perspectiva interdisciplinaria. Revista Estudios de Cultura Náhuatl, Vol. 35, p. 179-206, 2004. Disponível em: http://www.historicas.unam.mx/publicaciones/revistas / nahuatl/pdf/ecn35/711.pdf Acesso em: 21 abr. 2020.

HORCASITAS, Fernando. (1992). Nábuatl práctico. Lecciones y ejercicios para el principiante. $3^{a}$ edição. México: Universidad Nacional Autónoma de México, 1998. Disponível em: http://www.vcn.bc.ca/prisons/horcasitas.pdf Acessado em: 21/03/2020.

JAKOBSON, Roman. Lingüistica y poética. In: Ensayos de lingüística general. Tradução de Josep M. Pujol e Jem Cabanes. Madrid: Ed. Seix Barral, 1981, p. 347-395.

JOHANSSON, Patrick K. Tamoanchan: una imagen verbal del origen. Revista Estudios de Cultura Nábuatl, vol. 49, p. 59-92, 2015. Disponível em: http:/ /www.historicas.unam.mx/ publicaciones/revistas/nahuatl/pdf/ecn49/989.pdf Acesso em: 05 abr. 2020.

JOHANSSON, Patrick K. Nenomamictiliztli. El suicidio en el mundo náhuatl prehispánico. Revista Estudios de Cultura Nábuatl, vol. 47, p. 53-119, 2014b. Disponível em: http:/ / www.historicas.unam.mx/publicaciones/revistas/nahuatl/pdf/ecn47/960.pdf Acesso em: 06 set. 2020.

KIRCHHOFF, Paul. Mesoamérica: sus límites geográficos, composición étnica y caracteres culturales. Revista Acta Americana, p. 92-107, 1943.

LAUNEY, Michel. Introducción a la lengua y a la literatura nábuatl. Tradução de Cristina Kraft. México: Universidad Nacional Autónoma de México, Instituto de Investigaciones Antropológicas, 1992.

LELIS, Sara. Tradução de poesia nahuatl. Uma busca por rastros performáticos. Revista Grau Zero, v. 7, n. 2, 2019, p. 133-155. Disponível em: https:/ /www.revistas.uneb.br/index. php/grauzero/article/view/6520 Acesso em: 06 set. 2020. 
LELIS, Sara; ROSSI, Ana. Entrevista com Marcos Caroli Rezende: Tradutor de cantos em náhuatl para o português. Revista Rónai - Estudos Clássicos e Tradutórios, vol. 8, n. 1, p. 126-132, 2020. Disponível em: https://periodicos.ufjf.br/index.php/ronai/article/ view/30276/20842 Acesso em: 05 set. 2020.

LEÓN-PORTILLA, Miguel. Prefacio. In: Compendio de gramática nábuatl. $3^{a}$ edição. México: Universidad Nacional Autónoma de México, 2017, p. 5-8.

LOCKHART, James. Nahuatl as written. California: Stanford University Press, 2001.

LÓPEZ AUSTIN, Alfredo; LÓPEZ LUJAN, Leonardo (1996). Elpasado indígena. $3^{\text {a }}$ edição, $1^{a}$ reimpressão. México: FCE, Colmex, FHA, 2018.

MIGNOLO, Walter (1995). El lado más oscuro del renacimiento. Alfabetización, territorialidad y colonización. Tradução de Cristóbal Gnecco. Popayán: Universidad del Cauca, Sello Editorial, 2016.

MONTES DE OCA, Mercedes. El paralelismo y la construcción de escenas en un texto nahua. In: Mapas del cielo y la tierra. Espacio y territorio en la palabra oral. Editora Mariana Masera. México: Universidad Nacional Autónoma de México, 2014, p. 201-225.

MOTOLINÍA, Toribio de Benavente (c. 1555). Memoriales o Libro de las cosas de la Nueva España y de los naturales della. México: na casa do editor, Luis Garcia Pimentel, 1903. Disponível em: https://archive.org/details/memorialesdefra00sngoog/page/n9/mode/2up/ search/principales+fiestas Acesso em: 11 nov. 2019.

REZENDE, Marcos Caroli. Dezoito cantos em nábuatl. Florianópolis: UFSC, 1995.

SAHAGÚN, Bernardino (Frei) (1577). Historia General de las cosas de Nueva España. Edição com numeração, anotações, apêndices e paleografia por Ángel María Garibay Kintana. México: Porrúa, 2016.

SAUTRON, Marie. In: izquixochitl in cacahuaxochitl. Presencia y significación de un binomio floral en el discurso Poético náhuatl prehispánico. Revista Estudios de Cultura Nábuatl, vol. 38, p. 243-264, 2007. Disponível em: http://www.historicas.unam.mx/publicaciones / revistas/nahuatl/pdf/ecn38/778.pdfAcessado em: 06/09/2020.

SULLIVAN, Thelma (1976). Compendio de gramática nábuatl. $3^{a}$ edição. México: Universidad Nacional Autónoma de México, 2017. Disponível em: http:/ /www.historicas.unam.mx/ publicaciones/publicadigital/libros/gramatica/cgn_001.pdf Acesso em: 21 mar. 2020.

TRONCOSO PÉREZ, Ramón. "Nepantla": una aproximación al término. In: Tierras prometidas: de la colonia a la independencia. Coordenação de Bernat Castany Prado.Madrid: Centro para la Edición de los Clásicos Españoles; Bellaterra [Sardañola del Vallés]; Universidad Autónoma de Barcelona, 2011, p. 375-398.

WRIGHT CARR, David Charles. Lectura del Nábuatl. Versión revisada y aumentada. Ciudad de México: Instituto Nacional de Lenguas Indígenas, 2016. Disponível em: https://site. inali.gob.mx/publicaciones/libro_lectura_nahuatl/pdf/lectura_del_nahuatl.pdf Acessado em: 22/03/2020. 


\section{Anexos}

\section{Folhas 17f a 18f dos Cantares mexicanos}

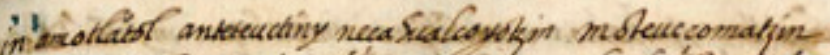

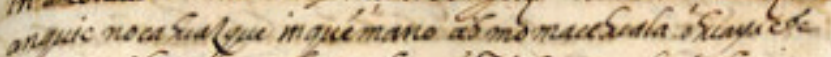

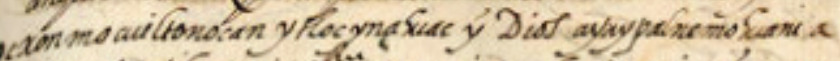

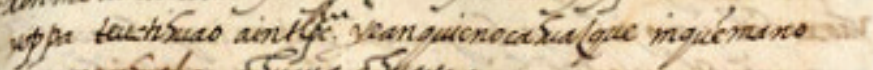

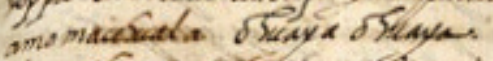

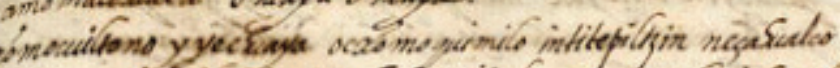

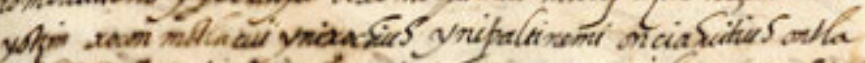

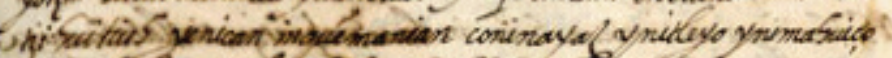

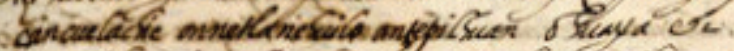

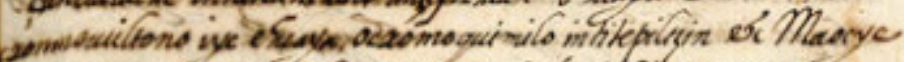

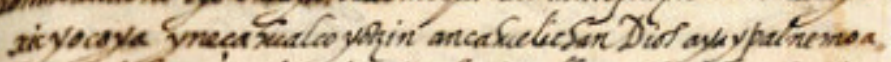

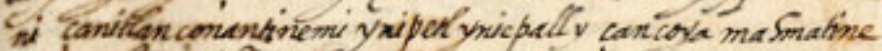

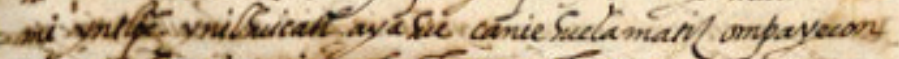

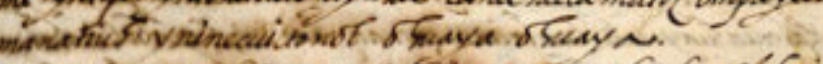

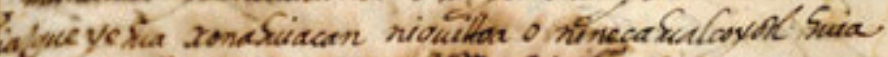

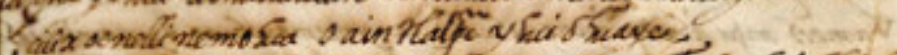

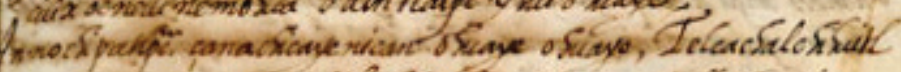

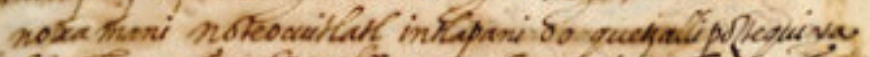

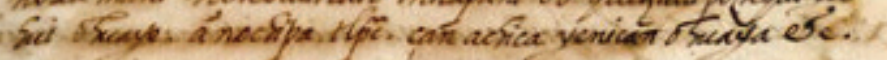

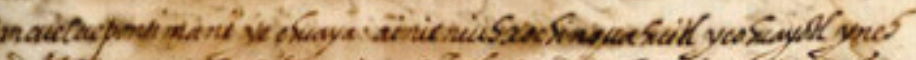

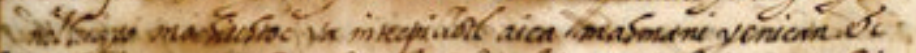

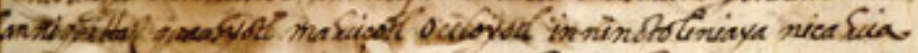

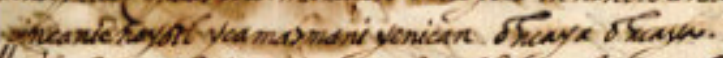

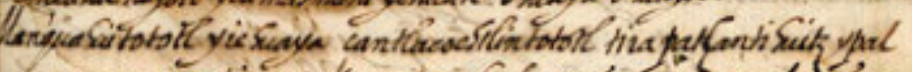

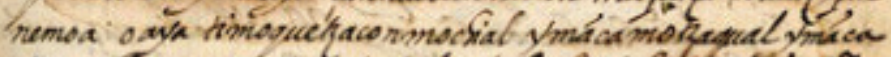

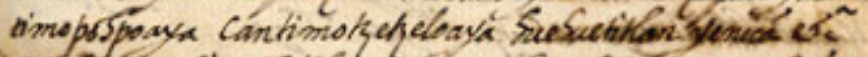

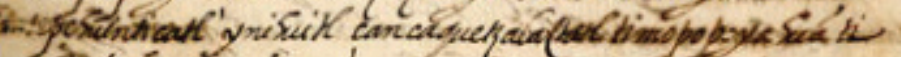

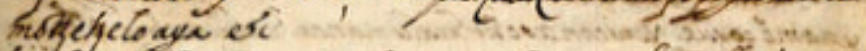

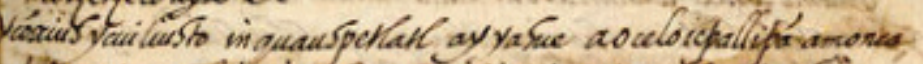

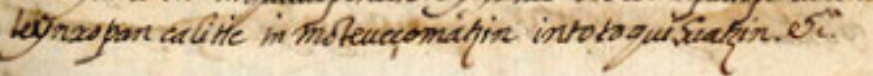
is usinis 


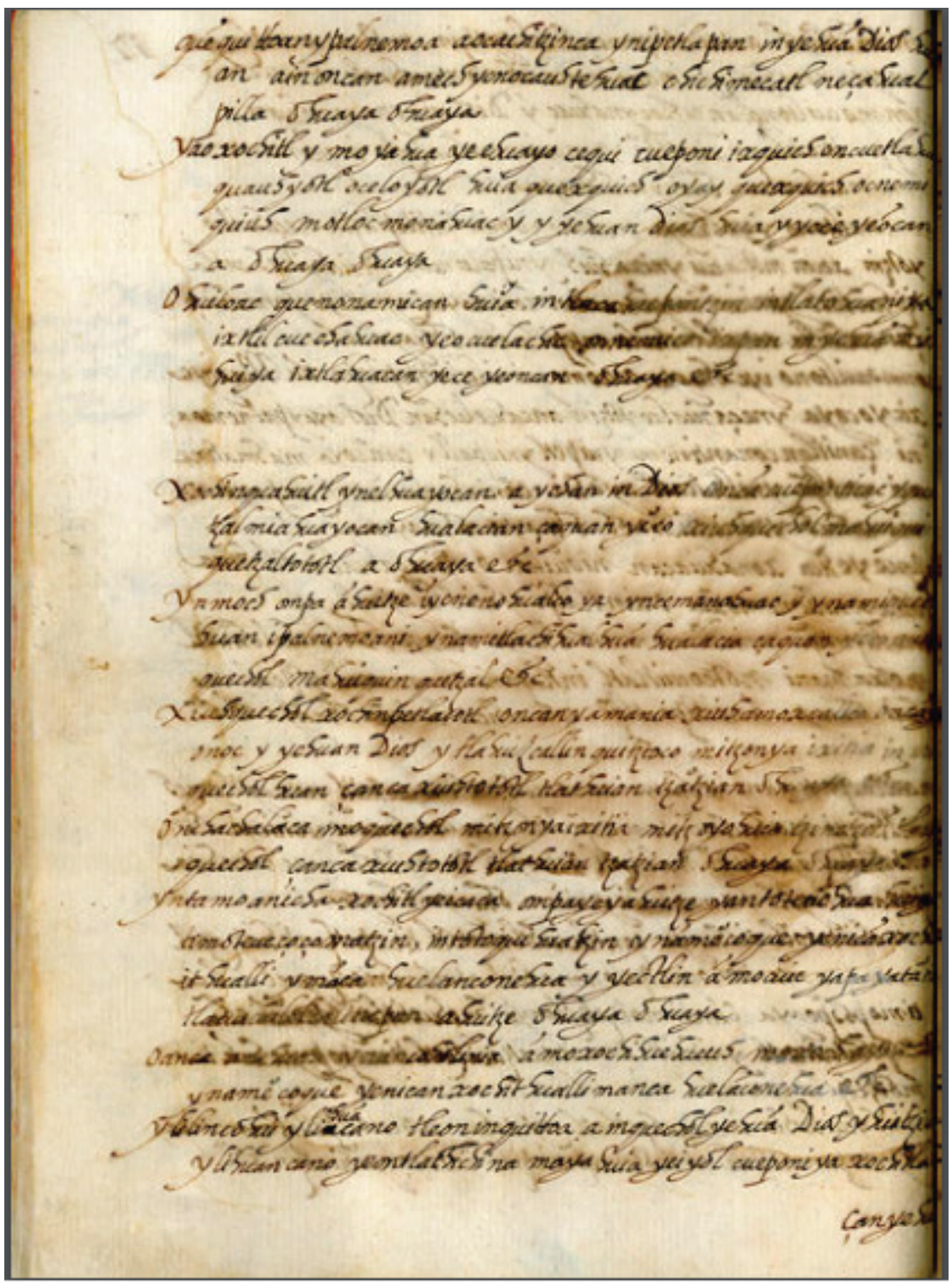




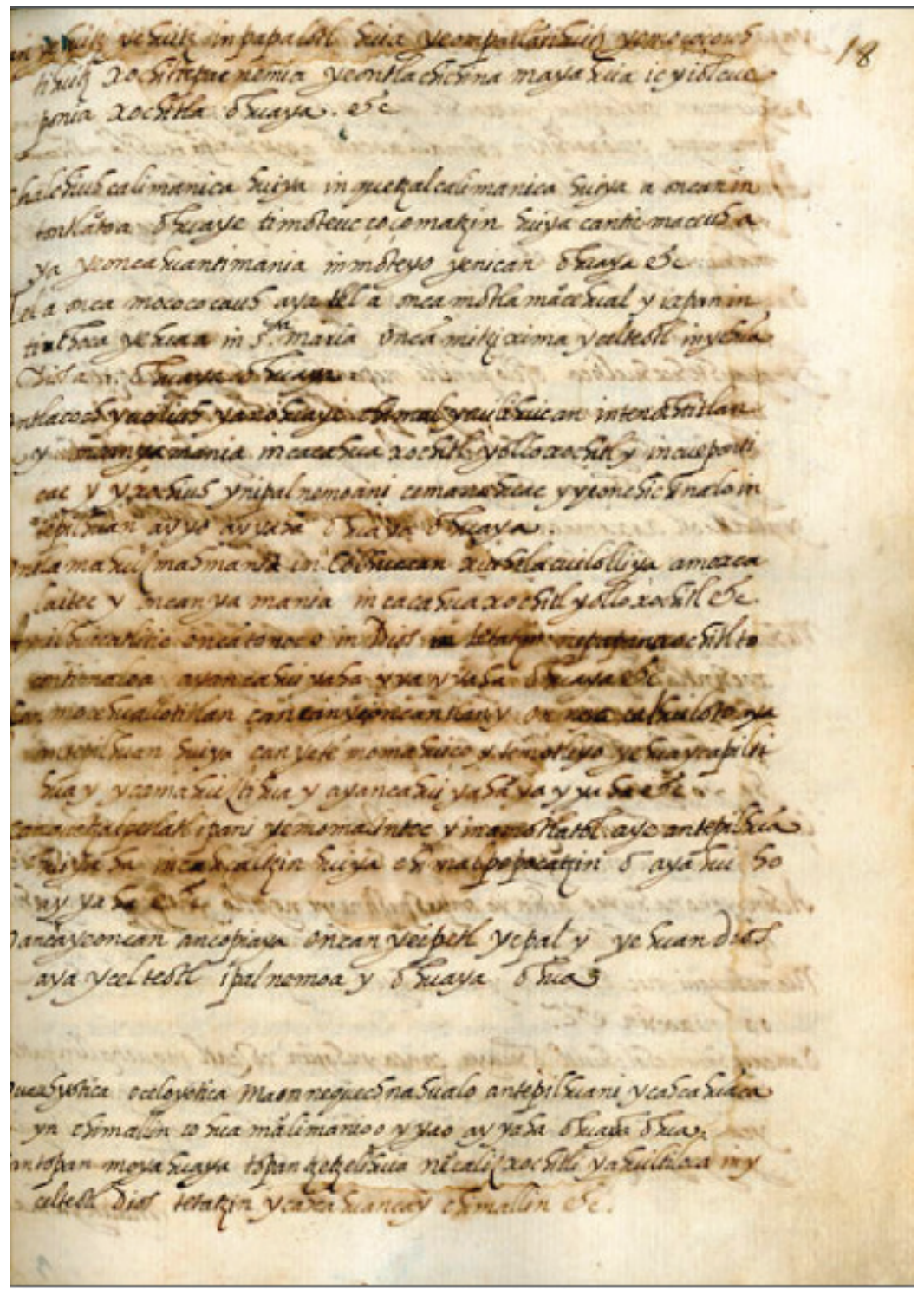

Folha 18 frente 